\title{
ANALISIS KEMAMPUAN PROSES PELAPISAN POLYUREA PADA ACRYLIC DENGAN KETEBALAN TERTENTU TERHADAP SIFAT MEKANIK
}

\author{
Jason Arie Putra, Erwin Siahaan dan Steven Darmawan \\ Laboratorium Metalurgi Fisik, Jurusan Teknik Mesin, Fakultas Teknik, Universitas Tarumanagara \\ e-mail: Jason_arie_ap@yahoo.com
}

\begin{abstract}
Coating became quite common. The coating serves as a conduit of color and also to cover the base material. Polyurea coating is a new innovation in the field of industry, so far polyurea coatings are used to coat the walls of the building and also the roof of the building to tackle the problem of leakage. This study explains how large the influence of the Polyurea coatings to acrylic. In this study which is distinguished by variations in thickness $3 \mathrm{~mm}$ acrylic, $5 \mathrm{~mm}$ and $8 \mathrm{~mm}$. This study also discusses the tensile resilience and resistance to shock loads. The purpose of this study was to determine how much influence the Polyurea coatings by comparing with Polyurea acrylic coated and uncoated. As an example of the results obtained from tensile tests that $3 \mathrm{~mm}$ acrylic coated and uncoated increased by $39.6 \%$ acrylic $5 \mathrm{~mm}$ by $0.66 \%$ and $1.65 \%$ acrylic $8 \mathrm{~mm}$. Polyurea coatings can not deliver maximum results on specimens that have smooth surfaces, so that we can see that in every test carried downhill result.
\end{abstract}

Keywords: acrylic, polyurea coating, tensile test

\begin{abstract}
Abstrak: Pelapisan menjadi hal yang cukup umum. Pelapisan berfungsi sebagai pemberi warna dan juga untuk menutupi material dasar. Pelapisan polyurea merupakan suatu inovasi baru dalam bidang perindustrian, selama ini pelapis polyurea digunakan untuk melapisi dinding bangunan dan juga atap bangunan untuk menanggulangi masalah kebocoran. Penelitian ini menjelaskan seberapa besar pengaruh dari pelapisan Polyurea terhadap acrylic. Dalam penelitian ini yang dibedakan adalah ketebalan acrylic dengan variasi $3 \mathrm{~mm}, 5 \mathrm{~mm}$, dan $8 \mathrm{~mm}$. Penelitian ini juga membahas mengenai ketahanan tarik dan ketahanan terhadap beban kejut. Tujuan dari penelitian ini adalah untuk mengetahui seberapa besar pengaruh pelapisan Polyurea dengan cara membandingkan antara acrylic yang dilapisi dengan Polyurea dan yang tidak dilapisi. Sebagai contoh hasil yang di dapat dari pengujian tarik bahwa acrylic 3mm yang telah dilapisi dan yang tidak dilapisi mengalami peningkatan sebesar 39,6\% acrylic $5 \mathrm{~mm}$ sebesar 0,66\% dan acrylic 8mm sebesar 1,65\%. Pelapis polyurea tidak dapat memberikan hasil yang maksimal pada spesimen yang memiliki permukaan yang halus, sehingga dapat kita lihat bahwa dalam setiap pengujian yang dilakukan hasilnya menurun.
\end{abstract}

Kata kunci : acrylic, pelapis polyuria, pengujian tarik

\section{PENDAHULUAN}

Dewasa ini, dunia dihadapkan dengan pesatnya perkembangan teknologi dan pengetahuan yang baru. Hal ini mendorong berbagai pihak untuk ikut serta membuat banyak penemuan berkaitan dengan ilmu pengetahuan yang sudah ada. Beberapa teknologi dan pengetahuan baru yang berkaitan dengan bidang keilmuan teknik mesin adalah membahas mengenai perancangan suatu alat, mengembangkan alat yang sudah ada, membuat jenis material baru, dan sebagainya. Namun dari semua pembahasan pada akhirnya akan mengacu kepada jenis material yang digunakan.

Pembahasan mengenai kekuatan material atau keunggulan suatu material, dapat dipelajari dan dilihat pada spesifikasi suatu material saat pembelian. Suatu material dapat dilakukan berbagai proses. Dalam bidang keilmuan teknik mesin terdapat beberapa macam perlakuan yang dapat dilakukan terhadap suatu material. Sebagai contoh, ada proses perlakuan panas pada suatu material, ada pula proses pencampuran berbagai macam material untuk mendapatkan spesifikasi yang diinginkan, ada pula yang mempelajari bagaimana menanggulangi reaksi kimia terhadap alam.

Oleh karena itu, pada skripsi ini bertujuan untuk membuat salah satu atau lebih dari contoh perlakuan pada suatu material. Jenis perlakuan yang diinginkan dapat menanggulangi reaksi kimia terhadap alam dan juga menambah kekuatan suatu material terhadap beban kejut (impact) dengan tidak merubah material dasar dan tidak menambahkan material dasar sehingga struktur kimia dan sifat fisik tetap utuh sesuai spesifikasi pabrik. Acrylic merupakan bahan yang akan dipergunakan pada penelitian ini. Acrylic merupakan material yang mudah didapat dan sering digunakan dalam pembuatan alat menelitian. Dibalik keuntungan yang banyak, acrylic juga memiliki sifat getas dan 
mudah hancur dibagian sisi. Untuk menanggulangi sifat getas acrylic, dilakukan pelapisan pada acrylic tersebut. Pada penelitian ini pelapisan akan menggunakan polyurea. Pelapisan polyurea merupakan suatu inovasi cukup baru di berbagai bidang. Pelapis polyurea merupakan uniqe coating dikarenakan selain melapisi material, juga memberikan pengaruh terhadap sifat mekanik material yang dilapisi. Pelapisan polyurea mulai dikembangkan pada sector pembangunan gedung agar dapat menambah kekuatan dari gedung dan tidak mudah runtuh sehingga tidak membahayakan lingkungan sekitar. Pada penelitian ini akan meninjau seberapa besar pengaruh pelapisan polyurea terhadap acrylic dan juga seberapa besar pengaruh pelapisan polyurea terhadap ketebalan acrylic.

\section{COATING}

Pelapis digunakan untuk menambah nilai estetika, melindungi material dari korosi, panas, aus, dan sebagainya hingga menambah umur layak material tersebut. Pemakaian coating sudah menjadi hal yang umum. Sebagai contoh, kita sering melihat benda-benda disekitar kita dilapisi oleh cat atau coating mulai dari jembatan, tangki air, mobil, pesawat, baja struktur, kapal, kayu, mebel, blok beton, peralatan listrik, dinding, dan sebagainya. Hal yang menentukan sifat-sifat suatu coating adalah komposisi dari coating itu sendiri. Tar coating merupakan coating paling tua yang pernah digunakan pada oil and gas transmisi pipa[1]. Beberapa dominan kualitas dapat tahan air dan embun, tahan korosi, murah, dan mudah digunakan. Fuxioan bonded epoxy coating merupakan serbuk coating adalah sebagai pelapis bubuk yang sering berlaku dengan taburi elektrostatik pada pipa mempersiapkan hangat[1]. Lapisan ini memiliki sifat mekanik dan fisik yang baik dan ikuti dengan coating uretan telah digunakan pada pipa dipasang di permukaan bumi. Fusion bonded epoxy coatings untuk penyerapan air tertentu rapuh dan kecenderungan dalam suhu tinggi. Juga, sebagian besar dari mereka telah digunakan untuk pipa dipasang melapisi di lingkungan[1]. Umumnya coating mengandung empat bahan dasar, yaitu binder, pigmen, solven, dan aditif[2]. Sangatlah penting bagi kita yang akan membuat coating untuk memahami fungsi dari bahan-bahan dasar ini.

\section{Binder (Bahan Pengikat)}

Binder berfungsi sebagai pengikat antar komponen coating. Terdapat banyak binder yang telah umum digunakan, diantaranya alkyd, vinyl, resin alam, epoxy, dan urethane[3]. Hal yang perlu diketahui tentang binder adalah bagaimana mereka mengalami curing. Pada umumnya binder dapat mengalami curing dengan dua cara. Pertama adalah melalui evaporasi solven. Binder yang mengalami curing seperti ini disebut binder thermoplastic atau non-covertible. Kedua adalah lewat reaksi kimia selama atau setelah proses pengecatan. Binder ini dikenal sebagai binder thermosetting.

Selain itu, hal yang harus dipahami dari binder adalah viskositas. Dikarenakan merupakan komponen utama dalam coating, viskositas binder sangat menentukan viskositas coating. Coating harus mempunyai viskositas cukup rendah untuk bisa digunakan dengan peralatan pengecatan sederhana (brush, roller, or spray) serta memiliki viskosita cukup tinggi sehingga tidak menetes. Faktor utama yang menentukan viskositas binder adalah berat molekularnya. Polimer yang mempunyai berat molekul tinggi akan lebih viskos dari pada berat molekul rendah. Ada dua cara untuk mengontrol viskositas suatu coating, yaitu dengan memvariasi berat molekul binder atau dengan menambahkan sejumlah solven

\section{Pigmen (Bahan Pewarna)}

Pigmen merupakan pemberi warna dari coating. Selain berfungsi dalam hal estetika, pigmen juga mempengaruhi ketahanan korosi dan sifat fisik dari coating itu sendiri. Pigmen dapat dikelompokan menjadi pigmen organik dan anorganik. Pigmen anorganik contohnya adalah Titanium Dioksida $\left(\mathrm{TiO}_{2}\right)$. $\mathrm{TiO}_{2}$ merupakan pigmen putih yang paling banyak digunakan, biasanya untuk coating eksterior[4]. $\mathrm{TiO}_{2}$ mempunyai indeks refleksi yang tinggi dan stabil terhadap sinar 
ultraviolet dari sinar matahari yang dapat mendegradasi binder coating. Terdapat juga extender pigmen yang memberikan sedikit pengaruh terhadap warna dan ketahanan korosi namun banyak mempengaruhi sifat-sifat coating seperti densitas, aliran, dan hardness. Contohnya adalah kalsium karbonat, kaolin, talc, dan barium sulfat.

\section{Solven (Bahan Pelarut)}

Kebanyakan coating memerlukan solven untuk melarutkan binder dan memodifikasi viskositas. Hal penting yang harus dilakukan dalam penentuan solven adalah kemapuanya untuk melarutkan binder dan komponen coating yang lain. prinsip kelarutan sangatlah sederhana, yaitu solven polar akan melarutkan senyawa yang polar. Selain itu laju penguapan solven juga perlu diperhatikan. Solven yang mempunyai tekanan uap tinggi sehingga menguap dengan cepat disebut fast atau hot solven, sedangkan yang lambat disebut slow solven.

\section{Aditif (Bahan Tambahan)}

Aditif merupakan senyawa-senyawa kimia yang biasa ditambahkan dalam jumlah sedikit, namun sangat mempengaruhi sifat coating. Bahan-bahan yang termasuk aditif adalah surfaktan, anti-setting agent, coalescing agents, catalysts, ultraviolet light absorbers, dispersing agents, dan plasticizers.

\section{Polyurea}

Polyurea adalah jenis elastomer yang berasal dari reaksi antara isosianat dan resin komponen campuran sintetis melalui polimerisasi pertumbuhan. Isosianat dapat aromatik atau alifatik di alam. Hal ini dapat monomer, polimer, atau reaksi varian isosianat, prepolimer atau prapolimer. Prapolimer, atau prepolimer, dapat dibuat dari resin polimer amina diawal, atau resin polimer hidroksil diakhiri[5].

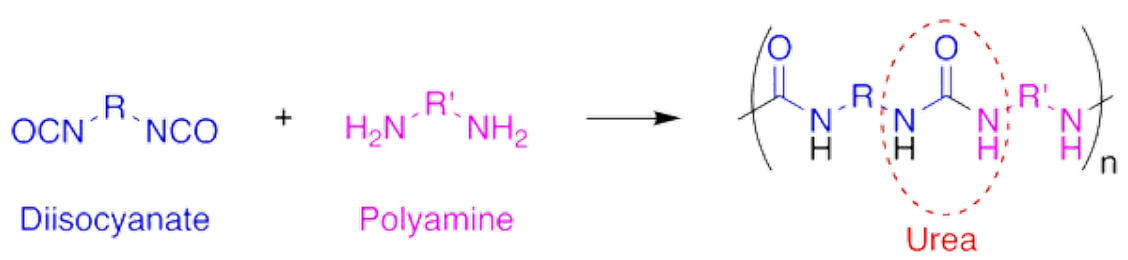

Gambar 1. Struktur kimia polyurea[6]

\section{METODE PENELITIAN}

Penelitian yang dilakukan adalah berupa eksperimen yang bertujuan untuk mengetahui seberapa besar pengaruh yang diberikan oleh pelapis polyurea terhadap acrylic. Menggunakan pelapis polyurea diakibatkan oleh mencari alternatif baru untuk material treatmen yang sedang dikembangkan dan juga Penelitian yang dilakukan mengacu pada standar pengujian ASTM D638-02a untuk tensile ASTM D 256 untuk pengujian impact.

\section{Diagram Alir}




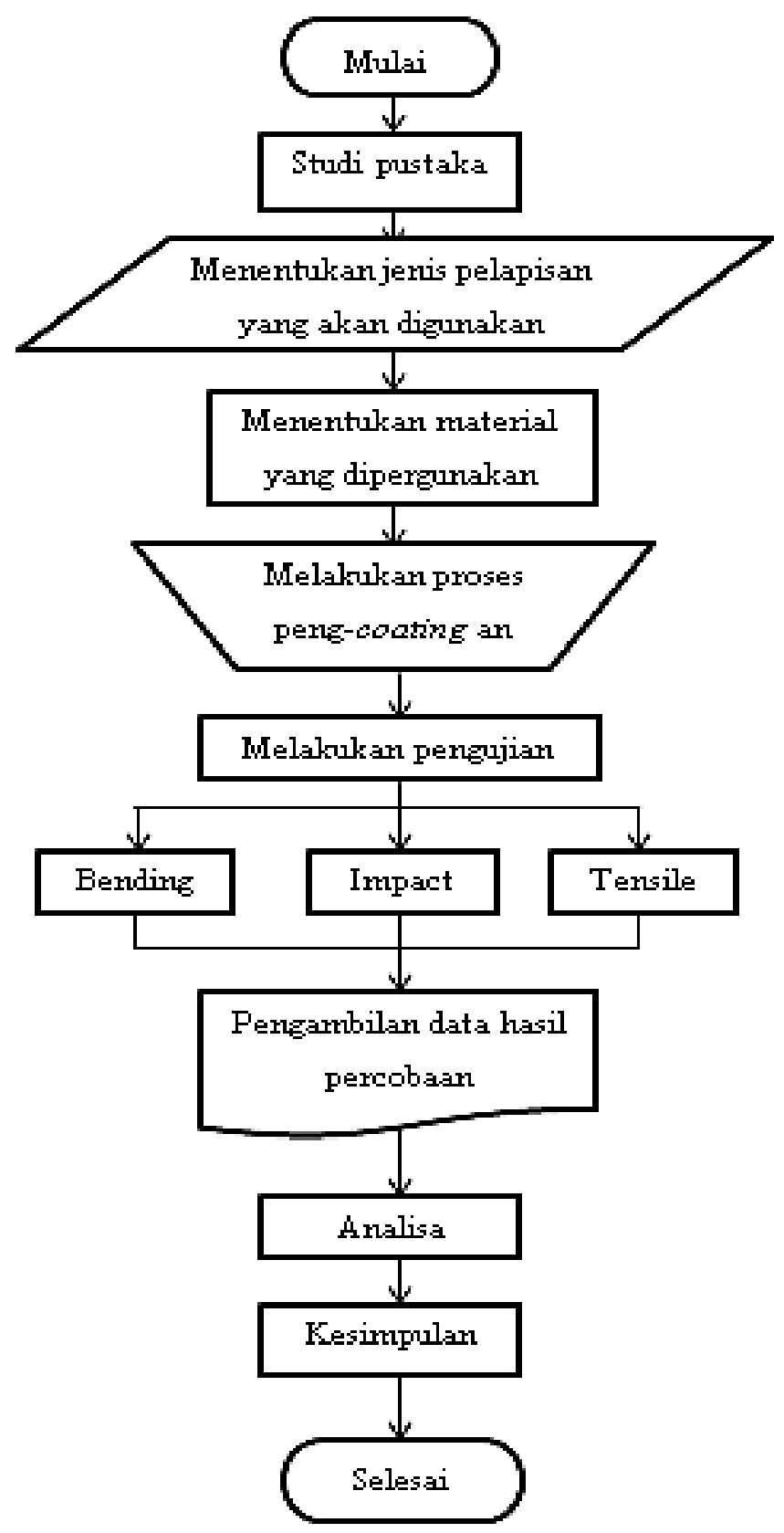

Gambar 1. Diagram alir penelitian

\section{Persiapan Spesimen Uji}

Sebagai persiapan awal adalah membuat spesimen uji. Sebelum membuat spesimen uji, tentukan ASTM yang akan dipergunakan. Setelah mendapatkan ASTM, buatlah spesimen sesuai standart yang telah di tentukan. Pemotongan spesimen agar lebih presisi menggunakan lasser cutting. Acrylik dibuat sebanyak 12 buah, dengan beberapa jenis, yaitu: Acrylik 3mm, 5mm, dan $8 \mathrm{~mm}$.

- 2 buah untuk pengujian tensile

- 2 buah untuk pengujian impact

\section{Proses Pengujian Spesimen}

Setelah selesai mempersiapkan spesimen yang telah selesai di coating, maka tahap berikutnya adalah proses pengujian. Dalam proses pengujian impact dan tensile dilakukan di laboratorium Universitas Tarumanagara (UNTAR), Jakarta. 


\section{Prosedur Pengujian tensile}

1. Tahap pertama adalah siapkan spesimen acrylik yang akan di uji tensile.

2. Spesimen yang akan diuji pertama kali adalah acrylik yang tidak di lapisi oleh coating Polyurea. Spesimen ini akan menjadi patokan dari spesimen acrylik yang sudah di lapisi dengan Polyurea.

3. Proses dimulai dengan menekan tombol on pada pump control dan memutar indikator load control pada posisi load. Pengujian dilakukan dengan skala pembebanan atau range 1,5 untuk seluruh spesimen

4. Proses pengamatan dilakukan dengan memperhatikan gerakan jarum indikator dengan mencatat posisi jarum saat terjadi yield dan ultimate stress.

5. Setelah spesimen mencapai ultimate strength, dilakukan penggantian ke spesimen selanjutnya. Sampai akhirnya ke enam spesimen uji acrylik telah selesai pengujian tensile.

\section{Prosedur Pengujian impact}

1. Pengujian impact dilakukan di Universitas Tarumanagara, dengan menggunakan alat impact tester machine. Bandul/takikan yang terdapat pada alat uji di cek apakah ada kerusakan atau tidak, kemudian tuas rem juga di cek terlebih dahulu. Langkah selanjutnya siapkan spesimen uji impact yang tidak dilapisi polyurea dan yang sudah dilapisi polyurea.

2. Spesimen di letakkan pada penahan dan diatur agar tegak lurus dengan bandul/takikkan sehingga bandul tepat mengenai bagian tengah spesimen.

3. Putar tuas untuk memutar bandul dan perhatikan jarum penunjuk derajat yang tertera pada alat uji. Atur posisi bandul hingga mencapai sudut $144^{\circ}$.

4. Lepaskan tuas penyangga bandul dan bersiap untuk melakukan pengereman setelah bandul mengenai spesimen uji yang telah di pasang pada penyangga.

5. Setelah bandul berhenti, bacalah jarum penunjuk derajat hasil pergerakan dari bandul kemudian catat derajar yang didapat.

6. Lakukan pengujian pada setiap spesimen yang telah disiapkan untuk pengujian impact.

\section{Hasil pengujian tensile}

Pada penelitian yang dilakukan menggunakan parameter pengujian yang sesuai dengan rekomendasi dari referensi yang didapat yaitu spesifikasi pengujian ASTM D638-02a untuk tensile.

Tabel 1. Hasil pengujian tensile

\begin{tabular}{|c|c|c|c|c|c|c|c|c|}
\hline Spesimen & $\begin{array}{c}\mathrm{t} \\
(\mathrm{mm})\end{array}$ & $\begin{array}{c}l \\
(\mathrm{~mm})\end{array}$ & $\begin{array}{c}\mathrm{Ao} \\
\left(\mathrm{mm}^{2}\right)\end{array}$ & $P_{y}(N)$ & $P_{u}(N)$ & $\varepsilon(\%)$ & $\sigma_{y}\left(\frac{N}{\mathrm{~mm}^{2}}\right)$ & $\sigma_{u}\left(\frac{N}{\mathrm{~mm}^{2}}\right)$ \\
\hline $3 \mathrm{~mm}$ & 3 & 19 & 57 & 2033,5 & 2597 & 0,014 & 35,675 & 45,561 \\
\hline $\begin{array}{c}3 \mathrm{~mm} \\
\text { coating }\end{array}$ & 4 & 21 & 84 & 3430 & 3479 & 0,156 & 40,833 & 41,4167 \\
\hline $5 \mathrm{~mm}$ & 5 & 18,5 & 92,5 & 4410 & 4655 & 0,085 & 47,676 & 50,324 \\
\hline $\begin{array}{c}5 \mathrm{~mm} \\
\text { coating }\end{array}$ & 6 & 19,13 & 114,78 & 4532,5 & 4998 & 0,114 & 39,4886 & 43,544 \\
\hline $8 \mathrm{~mm}$ & 8 & 19 & 152 & 5806,5 & 6149,5 & 0,185 & 38,258 & 41,126 \\
\hline $\begin{array}{c}8 \mathrm{~mm} \\
\text { coating }\end{array}$ & 10,2 & 20,5 & 209,1 & 7864,5 & 8599,5 & 0,114 & 37,611 & 40,457 \\
\hline
\end{tabular}

\section{Hasil Pengujian Impact}

Pada penelitian yang dilakukan menggunakan parameter pengujian yang sesuai dengan rekomendasi dari referensi yang didapat yaitu spesifikasi pengujian ASTM D256 untuk impact. 
Tabel 2. Hasil pengujian impact

\begin{tabular}{|c|c|c|c|c|c|c|c|c|}
\hline Spesimen & $\begin{array}{c}\mathrm{t} \\
(\mathrm{mm})\end{array}$ & $\begin{array}{c}l \\
(\mathrm{~mm})\end{array}$ & $\begin{array}{c}\text { Ao } \\
\left(\mathrm{mm}^{2}\right)\end{array}$ & $\alpha$ & $\beta$ & $G(\mathrm{~kg})$ & $\mathrm{L}(\mathrm{m})$ & $H I\left(\frac{\mathrm{J}}{\mathrm{mm}^{2}}\right)$ \\
\hline $3 \mathrm{~mm}$ & 2,55 & 12,35 & 31,5 & $144^{\circ}$ & $65^{\circ}$ & 26,12 & 0,75 & 7,85 \\
\hline $\begin{array}{c}3 \mathrm{~mm} \\
\text { coating }\end{array}$ & 4 & 12,75 & 51 & $144^{\circ}$ & $57^{\circ}$ & 26,12 & 0,75 & 5,0956 \\
\hline $5 \mathrm{~mm}$ & 4,65 & 12,4 & 57,66 & $144^{\circ}$ & $59^{\circ}$ & 26,12 & 0,75 & 4,41 \\
\hline $\begin{array}{c}5 \mathrm{~mm} \\
\text { coating }\end{array}$ & 6,85 & 14,35 & 98,29 & $144^{\circ}$ & $53^{\circ}$ & 26,12 & 0,75 & 2,755 \\
\hline $8 \mathrm{~mm}$ & 7,8 & 12,45 & 97,11 & $144^{\circ}$ & $60^{\circ}$ & 26,12 & 0,75 & 2,588 \\
\hline $\begin{array}{c}8 \mathrm{~mm} \\
\text { coating }\end{array}$ & 9,95 & 13,35 & 132,83 & $144^{\circ}$ & $54^{\circ}$ & 26,12 & 0,75 & 2,02 \\
\hline
\end{tabular}

\section{Hasil Pengujian Flexural}

Pada penelitian flexural menggunakan parameter pengujian yang sesuai dengan rekomendasi dari referensi yang didapat yaitu spesifikasi pengujian ASTM D790 untuk flexural.

Tabel 3. Hasil pengujian flexural

\begin{tabular}{|c|c|c|c|c|c|c|}
\hline Spesimen & $\begin{array}{c}\mathrm{t} \\
(\mathrm{mm})\end{array}$ & $\begin{array}{c}\text { Length } \\
(\mathrm{mm})\end{array}$ & Defleksi & $\begin{array}{c}\text { Beban } \\
\text { Load } \\
(k g f)\end{array}$ & $\sigma F\left(\frac{k g f}{\mathrm{~mm}^{2}}\right)$ & $\varepsilon_{f}$ \\
\hline $3 \mathrm{~mm}$ & 3 & 30 & 3 & 37,9 & 7,58 & 0,06 \\
\hline $\begin{array}{c}3 \mathrm{~mm} \\
\text { coating }\end{array}$ & 4 & 30 & 3 & 38,9 & 3,71 & 0,08 \\
\hline $5 \mathrm{~mm}$ & 5 & 30 & 1 & 54,9 & 8,235 & 0,03 \\
\hline $\begin{array}{c}5 \mathrm{~mm} \\
\text { coating }\end{array}$ & 7 & 30 & 2 & 67,2 & 3,63 & 0,093 \\
\hline $8 \mathrm{~mm}$ & 8 & 30 & 2 & 113,4 & 6,815 & 0,107 \\
\hline $\begin{array}{c}8 \mathrm{~mm} \\
\text { coating }\end{array}$ & 9 & 30 & 2 & 120,2 & 4,2 & 0,12 \\
\hline
\end{tabular}

\section{Analisis Mikroskop Optik}

Spesimen hasil pengujian tensile diamati dengan menggunakan mikroskop digital menggunakan perbesaran 50x untuk spesimen 3mm. Pengambilan gambar mikroskopik menggunakan microscopic camera system yang terintegrasi antara komputer dan mikroskop digital. Gambar dibawah merupakan gambar hasil patahan dari speseimen $3 \mathrm{~mm}$ tensile yang telah dilapisi oleh polyurea. Dapat dilihat bahwa patahan yang dihasilkan tidak memperlihatkan adanya pertambahan panjang. Jenis patahan yang dihasilkan merupakan patah getas (brittle).

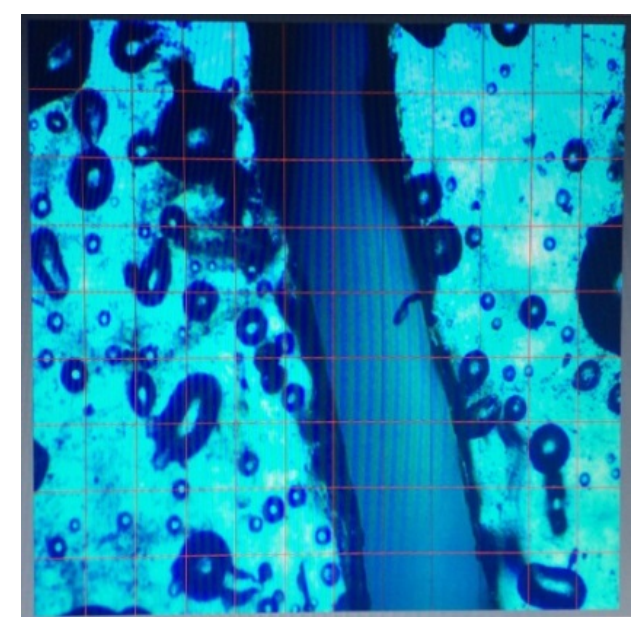

Gambar 1. Spesimen tensile 3mm dengan pelapis 


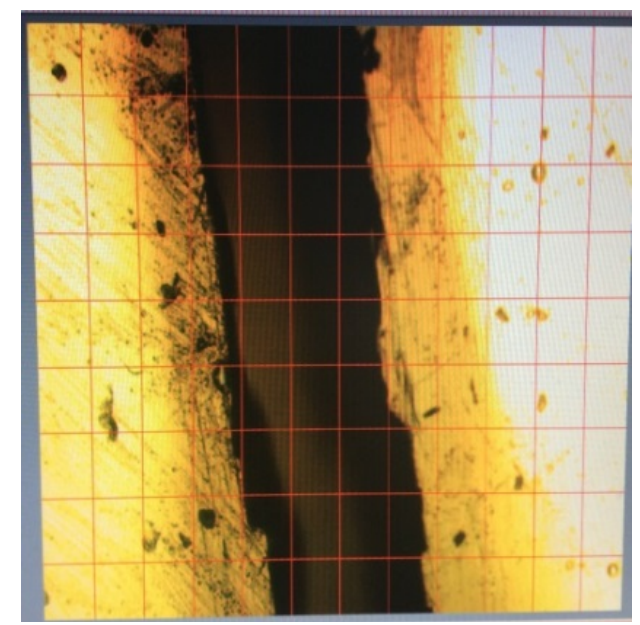

Gambar 2. Spesimen tensile 3mm tanpa pelapis

Berdasarkan pengamatan mikroskopik dan makroskopik yang dilakukan pada spesimen hasil uji tarik, didapatkan profil patahan pada masing-masing spesimen 3mm yang dilapisi dan 3mm yang tidak dilapisi. Patahan pada spesimen 3mm yang dilapisi dan yang tidak dilapisi terjadi pada daerah gage length. Berdasarkan pengamatan, patahan yang terjadi berupa satu garis hampir lurus. Berdasarkan pengamatan mikroskop, patahan yang terjadi pada spesimen 3mm dengan dilapisi polyurea terdapat beberapa titik seperti rambut yang dihasilkan dari pelapis polyurea. Sedangkan berdasarkan pengamatan mikroskopik terhadap patahan pada specimen 3mm tanpa dilapisi mengalami patahan yang lurus, tetapi ada beberapa titik patahan terdapat pecahan dari acrylic. Pengamatan pada spesimen $3 \mathrm{~mm}$ dengan pelapis polyurea dan $3 \mathrm{~mm}$ tanpa pelapis polyurea menunjukkan patah getas (Brittle).
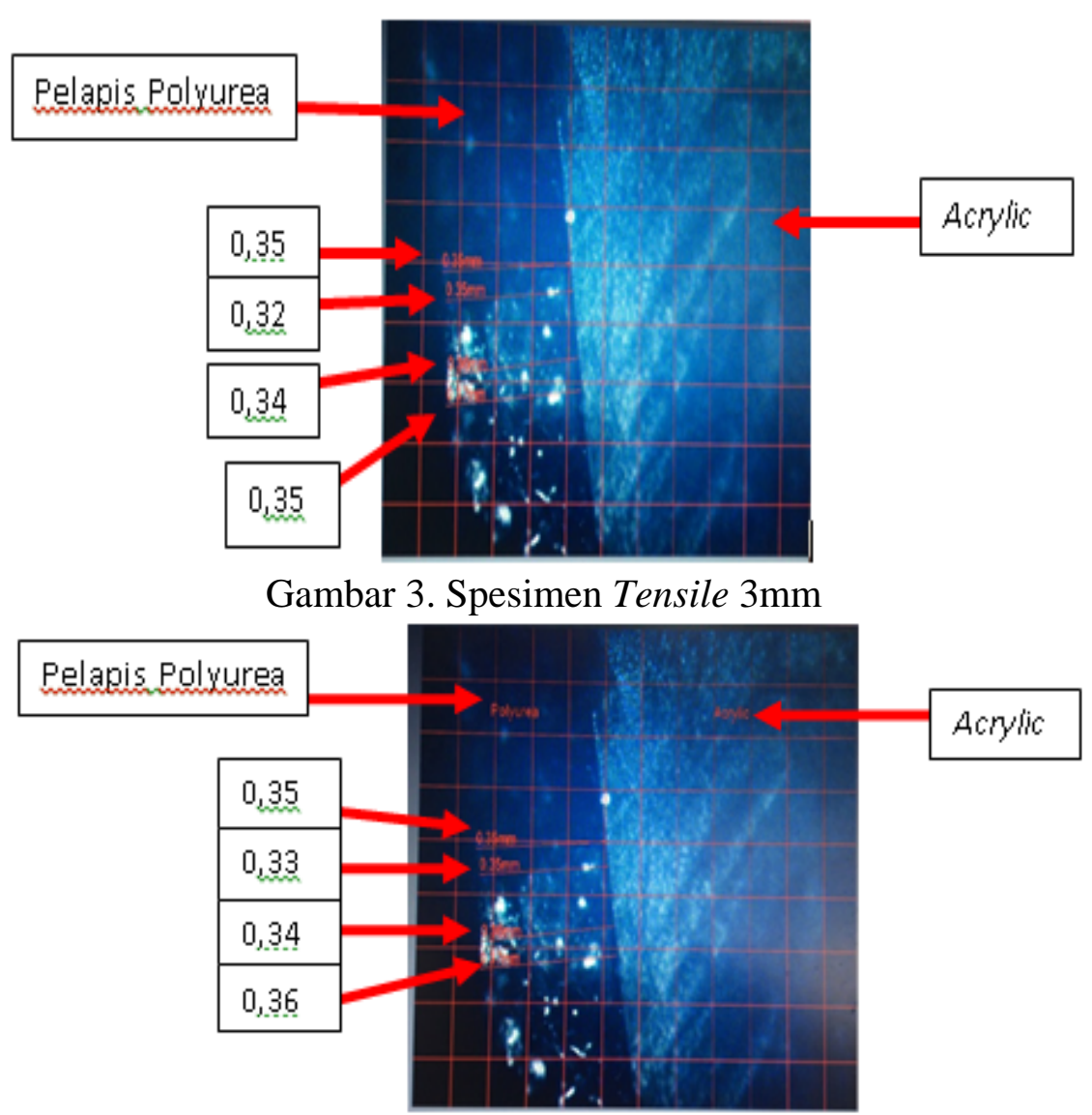

Gambar 4. Spesimen Tensile 5mm 


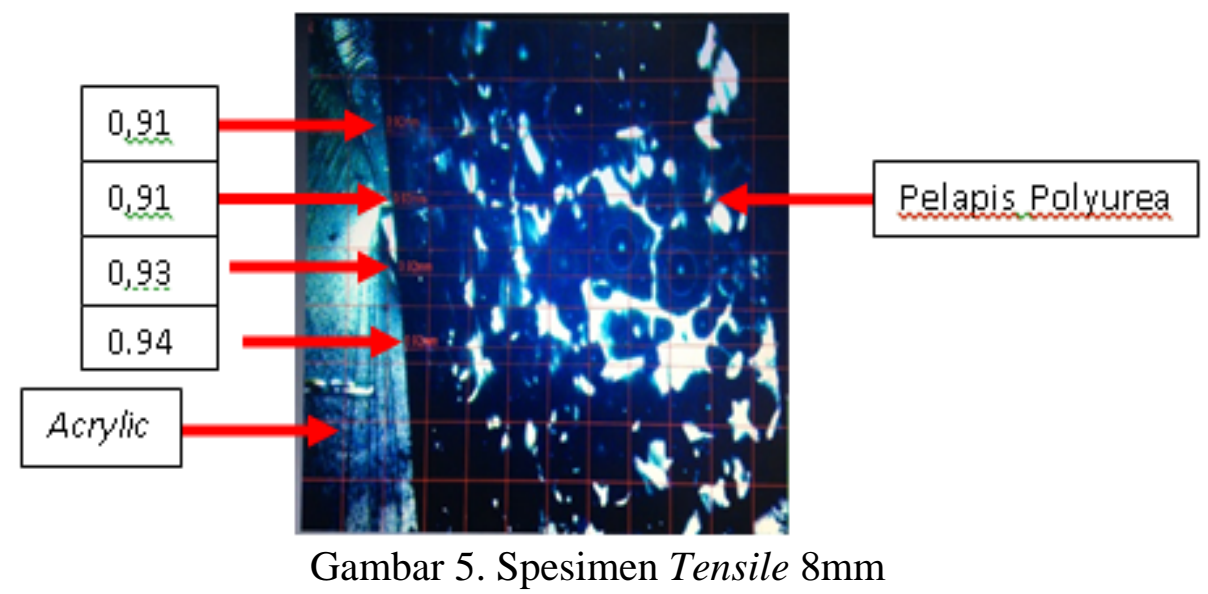

Berdasarkan gambar 3, 4, dan 5 dapat dilihat ketebalan pelapis polyurea yang dipergunakan. Ketebalan pelapis polyurea berbeda, dikarenakan saat proses penyemprotan spesimen tidak dapat menahan tekanan dari spraygun sehingga spesimen terhempas. Perbedaan juga terlihat antara spesimen $3 \mathrm{~mm}$ dan $5 \mathrm{~mm}$ dengan spesimen $8 \mathrm{~mm}$. Ketebalan pelapis polyurea juga cukup jauh, dikarenakan saat penyemprotan spesimen $8 \mathrm{~mm}$ lebih stabil sehingga penyemprotan yang dilakukan lebih baik.

\section{KESIMPULAN}

Setelah pengujian tensile didapat dari data bahwa kekuatan tarik acrylic meningkat seiring dengan bertambahnya ketebalan dan juga kekuatan tarik acrylic yang telah di berikan pelapis polyurea meningkat tetapi penambahan yang terjadi tidak terlalu besar. Setelah pengujian impact didapat dari data, harga impact yang didapat menurun seiring dengan penambahan ketebalan acrylic. Harga impact dari acrylic yang telah diberikan pelapis polyurea lebih rendah dari acrylic yang tidak diberikan apapun. Patahan yang terjadi pada acrylic setelah diberikan beban tarik dan beban kejut, patah getas (brittle). Walaupun acrylic yang telah diberikan pelapis polyurea tetap mengalami patah getas (brittle).

\section{DAFTAR PUSTAKA}

[1] Amir Samimi (2012). "Use of Polyurethane Coating to Prevent Corrosion in Oil and Gas Pipelines Transfer”. Department of Chemical Engineering, Mahshahr Branch, Islamic Azad University, Mahshahr, Iran

[2] Gary E. Huggins. 1996. "Surface Coating Composition".

[3] Lee, H and K. Neville. 1956. Epoxy Resin, Their Application and Technology. New York: Mcgraw Hill.

[4] "polyurea for boats". http://www.polyureaforboats.co.uk. Retrieved 12 April 2015.

[5] Esti Handayani. (2010). "Studi Perlakuan Alkali Terhadap Kekuatan Impak dan Flexural Komposit Serat Rami Bermatrik Polyester Dengan Core Sekam Padi Bermatrik Urea Formaldehide”. Universitas Muhammadiyah Surakarta.

[6] Morison, R.T. and R.N. Boyd. 1973. Organic Chemistry. $3^{\text {rd }}$ ed., New Delhi: Prentice Hall. P.562-593. 